\title{
Avaliação do uso de filme plástico de policloreto de vinila (PVC) no armazenamento de cenouras
}

\author{
Evaluation of the use of plastic film of polyvinyl chloride (PVC) in \\ the storage of carrots
}

\author{
Ricardo Antonio Ayub ${ }^{1 *}$; Mariane Gioppo ${ }^{2}$; Marie Yamamoto Reghin ${ }^{1}$
}

\section{Resumo}

Em raízes de cenoura, a redução da porcentagem de massa e a ocorrência de doenças são as principais causas de perda pós-colheita durante o armazenamento e a comercialização. Também, a brotação e o enraizamento são apontados como os possíveis prejuízos ao uso da atmosfera modificada em hortaliças de raízes e tubérculos. O presente estudo foi realizado com o objetivo de comparar formas de embalagem e tempo de armazenamento sobre a perda de massa, porcentagem de raízes brotadas e concentração de $\beta$ caroteno em três cultivares de cenoura. As cenouras foram acondicionadas em bandejas rasas de poliestireno e embaladas com filme plástico de PVC, sendo acondicionadas duas raízes por bandeja, ou a granel. Em seguida, as raízes foram armazenadas no escuro em condições ambiente durante 20 dias As cenouras armazenadas com filme plástico de (PVC) mantiveram-se viáveis comercialmente por até 12 dias. Quando armazenadas à granel apresentaram perda de peso superior a 5\% em 4 dias, não sendo viável para o comércio. $\mathrm{O}$ teor de carotenóides foi constante em todo o período de armazenamento pra as três cultivares.

Palavras-chave: Daucus carota, pós-colheita, perda de peso, podridão, brotações

\begin{abstract}
Abstrat
In carrot roots, reducing the percentage of mass and the occurrence of diseases are the leading causes of post-harvest losses during storage and marketing. Also, budding and rooting are indicated as the possible effect on the use of modified atmosphere in root vegetables and tubers. This study was conducted to compare forms of packaging and storage time on weight loss, percentage of sprouted roots and concentration of $\beta$ carotene in three carrot cultivars. The carrots were placed in shallow trays of polystyrene and wrapped with PVC film, and put two roots per tray, or in bulk. Then, the roots were stored in the dark at ambient conditions for 20 days Carrots stored with plastic film (PVC) remained commercially viable for up to 12 days. When stored in bulk showed weight loss of more than $5 \%$ in 4 days, which is not feasible to trade. The content of carotenoids was constant throughout the storage period for the in three cultivars.
\end{abstract}

Key words: Daucus carota, postharvest, weight loss, rot, sprouting

\footnotetext{
${ }^{1}$ Professores Doutores do curso de Agronomia da Universidade Estadual de Ponta Grossa, UEPG, Departamento de Fitotecnia, Av. Carlos Cavalcanti 4748, 84030-900, Ponta Grossa - PR. E-mail: rayub@uepg.br; freghin@convoy.com.br

${ }^{2}$ Engenheira Agrônoma, Mestranda de Agronomia, Bolsista da Fundação Araucária, UEPG, Departamento. de Fitotecnia, Av. Carlos Cavalcante, 4748, 84030-900, Ponta Grossa - PR. E-mail: mariane@uepg.br

* Autor para correspondência
} 


\section{Introdução}

A cenoura (Daucus carota L.) é uma hortaliça da família Apiácea, do grupo das raízes tuberosas, cultivada em larga escala nas regiões Sudeste e Sul do Brasil. Os maiores produtores são os municípios de Carandaí, Maria da Fé, São Gotardo e Rio Paranaíba, em Minas Gerais, Piedade, Ibiúna e Mogi das Cruzes, em São Paulo, Ponta Grossa, no Paraná e Irecê na Bahia (OLIVEIRA et al., 2003). Em 2006, segundo informações da EMPRESA BRASILEIRA DE PESQUISA AGROPECUÁRIA - EMBRAPA CNPH, foram cultivados no Brasil 25,55 mil hectares de cenoura com produção de 750.050 toneladas (produtividade 29,36 $\mathrm{t} \mathrm{ha}^{-1}$ ). Além do aspecto econômico, a cenoura pode ser industrializada de diferentes formas e transformada em produtos destinados à alimentação humana, tais como conservas apertizadas, picles, congeladas, desidratadas, alimentos para bebês e sucos (CHITARRA; CARVALHO, 1984).

Após a colheita, várias hortaliças amplamente consumidas pela população perdem suas características físico-químicas e organolépticas em poucos dias, principalmente quando mantidas em condições ambientais (CARON; JACOMINO; KLUGE, 2003). Perdas de massa iguais ou superiores a 5\%, para a maioria das hortaliças, são capazes de produzir enrugamento, com conseqüente diminuição de sua aceitabilidade pelo consumidor (LUENGO; CALBO, 2001).

Em raízes de cenoura, a redução da porcentagem de massa e a ocorrência de doenças são as principais causas de perda pós-colheita durante o armazenamento e a comercialização (OLIVEIRA et al., 2001). A perda de massa é decorrência de altas taxas de transpiração das raízes, o que resulta na piora da aparência pela murcha e enrugamento da casca e pela alteração da textura, dentre outros (CARON; JACOMINO; KLUGE, 2003). Além disso, destacam-se as perdas proporcionadas pelo crescimento e desenvolvimento de microorganismos, como Erwinia e nematóides (MUKAI; KIMURA,
1986), que afetam negativamente a qualidade da cenoura, principalmente no verão, limitando a comercialização (OLIVEIRA et al., 2001).

Também, a brotação e o enraizamento são apontados como os possíveis prejuízos ao uso da atmosfera modificada em hortaliças de raízes e tubérculos, em função das alterações incontroláveis de umidade e na concentração de gazes que podem ocorrer na interior da embalagem (KADER, 1992).

A Secretaria de Estado da Agricultura, Pecuária e Abastecimento de Minas Gerais recomenda no seu programa de certificação da qualidade para cenoura a comercialização em embalagens plásticas. Para o estado do Paraná tal tipo de orientação não foi encontrado. Desta forma é preciso avaliar a viabilidade destes materiais em relação à vida útil pós-colheita da cenoura, considerando-se o armazenamento em condições não controladas (OLIVEIRA et al., 2001).

A pesquisa genética visando melhoria de qualidade e produtividade da cultura constantemente introduz novas cultivares de cenoura no mercado. No entanto, pouco se conhece sobre o comportamento pós-colheita desses materiais, carecendo, portanto, de pesquisas que demonstrem qual a melhor forma de conservação para cada cultivar.

O presente estudo foi realizado com o objetivo de comparar formas de embalagem e tempo de armazenamento sobre algumas variáveis em três cultivares de cenoura.

\section{Material e Métodos}

O experimento foi realizado em fevereiro de 2006 em Ponta Grossa, PR. Raízes de cenoura das cultivares Brasília,AF1620eAlvorada, recentemente colhidas foram lavadas em água corrente, secas ao ar e selecionadas entre 15 a $20 \mathrm{~cm}$ de comprimento. As cenouras foram acondicionadas em bandejas rasas de poliestireno $(21 \mathrm{~cm} \mathrm{x} 14 \mathrm{~cm})$ e embaladas com filme plástico de policloreto de vinila (PVC) com $12 \mu \mathrm{m}$ de espessura, sendo acondicionadas 
duas raízes por bandeja, ou a granel. Em seguida, as raízes foram armazenadas no escuro em condições ambiente durante 20 dias $\left(21,1\right.$ a $29,3^{\circ} \mathrm{C}$ e 35 a $85 \%$ de UR).

O delineamento experimental foi inteiramente casualizado, com quatro repetições em esquema fatorial triplo, sendo os fatores: três cultivares (Brasília, AF1620 e Alvorada), duas formas de armazenamento (a granel e embalada em PVC) e períodos de armazenamento (dias após o início do armazenamento). A unidade experimental para as avaliações de massa seca, perda de peso e $\beta$ caroteno foi constituída por um conjunto de duas raízes de cenoura e para as demais avaliações utilizou-se um conjunto de dez raízes de cenoura, todas com prévia identificação.

Com finalidade de caracterização, no inicio do experimento foi determinada a massa seca de oito amostras de cada cultivar, obtida pela secagem em estufa até atingir massa constante. A comparação da massa seca entre as cultivares nesta avaliação foi feita pelo teste de Tukey $(\mathrm{P} \leq 0,05)$ considerando um delineamento inteiramente casualizado.

A perda de massa das cenouras foi determinada pela razão entre a diferença da massa inicial das raízes e a massa na data das avaliações, sendo avaliada aos $2,4,6,8,10,12,14,16$ e 20 dias. A porcentagem de cenouras com pelo menos uma radicela maior que $5 \mathrm{~mm}$, porcentagem de cenouras com pelo menos um broto maior que $5 \mathrm{~mm}$ e porcentagem de cenouras podres foram determinadas em amostras de 10 cenouras aos $8,10,12,16$ e 20 dias, pois não haviam sinais de brotamento, enraizamento e podridões nas avaliações anteriores à de 8 dias. A concentração de $\beta$ caroteno foi obtida através da extração em éter de petróleo e determinação por espectrofotometria a $450 \mathrm{~nm}$ segundo as normas analíticas do Instituto Adolfo Lutz (1985). Esta avaliação foi realizada aos $0,5,10$ e 15 dias. O maior intervalo entre as avaliações deve-se ao fato de ser uma avaliação destrutiva. Aos 20 dias as cenouras não estavam mais em condições visuais de serem comercializadas, portanto a avaliação de $\beta$ caroteno não foi realizada.

Os dados foram submetidos à análise de variância e comparação de média pelo teste de Tukey ao nível de 5\% de probabilidade. Para período de armazenamento foi realizada análise de regressão polinomial e definido o melhor ajuste pela regressão de maior grau significativa ao nível de $5 \%$ de probabilidade. Para a realização das análises foi utilizado o programa Estat (KRONKA; BANZATTO, 1995). Os gráficos foram gerados no programa Microsoft Excel.

\section{Resultados e Discussão}

A caracterização inicial dos cultivares de cenoura revelou que a concentração de massa seca foi maior nas cultivares AF 1620 e Alvorada (100 e $108 \mathrm{~g} \mathrm{~kg}^{-1}$ ) em comparação com o cultivar Brasília $\left(90 \mathrm{~g} \mathrm{~kg}^{-1}\right)$. Maior massa seca inicial de raízes de cenoura foi obtida na 'Alvorada', sendo 20,2\% superior à obtida pela 'Brasília', porém não diferiu significativamente da 'AF 1620', estando de acordo com os resultados obtidos por Caron, Jacomino e Kluge (2003).

Para redução de massa fresca de raízes de cenouras, houve efeito significativo da interação entre os fatores cultivares e formas de armazenamento e entre forma e períodos de armazenamento.

Quando armazenadas a granel, as raízes de cenoura 'Alvorada' apresentaram maior redução na massa fresca em relação às demais cultivares, embora não tenha se diferenciado da 'Brasília' (Tabela 1). Por outro lado, quando embaladas em filme plástico de PVC não houve diferença de perda de massa fresca entre as cultivares, apresentando em média 3,98 g $100 \mathrm{~g}^{-1}$ ao final dos 20 dias de armazenamento. A maior massa seca observada na 'Alvorada' e 'AF 1620' não influenciou na menor redução de massa fresca em relação à cv Brasília. 
Tabela 1. Redução de massa fresca ( $\left.100 \mathrm{~g}^{-1}\right)$, porcentagem de raízes de cenouras com podridões embaladas em filme plástico de policloreto de vinila (PVC) ou a granel em função das cultivares, após 20 dias de armazenamento. Ponta Grossa, UEPG, 2007.

\begin{tabular}{lcc}
\hline & \multirow{2}{*}{ Cultivar } & \multicolumn{2}{c}{ A granel } & Embalada \\
\cline { 2 - 3 } & \multicolumn{2}{c}{ Redução de massa fresca } \\
\hline Brasília & $12,01 \mathrm{Aba}$ & $3,56 \mathrm{Ab}$ \\
Alvorada & $11,87 \mathrm{Ba}$ & $3,43 \mathrm{Ab}$ \\
AF1620 & $13,00 \mathrm{Aa}$ & $3,17 \mathrm{Ab}$ \\
\hline CV (\%) & \multicolumn{2}{c}{22,98} \\
\hline \multicolumn{4}{c}{ Porcentagem de raízes de cenoura com brotos } \\
\hline Brasília & $48,5 \mathrm{Ab}$ & $66,5 \mathrm{Aa}$ \\
Alvorada & $21,0 \mathrm{Bb}$ & $63,0 \mathrm{Aa}$ \\
AF1620 & $28,0 \mathrm{Bb}$ & $49,0 \mathrm{Ba}$ \\
\hline CV (\%) & \multicolumn{3}{c}{32,88} \\
\hline \\
Brasília & Porcentagem de raízes de cenoura com podridões \\
Alvorada & $0,0 \mathrm{Ab}$ & $10,8 \mathrm{Aa}$ \\
AF1620 & $2,0 \mathrm{Aa}$ & $5,0 \mathrm{ABa}$ \\
\hline CV (\%) & $0,0 \mathrm{Aa}$ & $0,4 \mathrm{Ba}$ \\
\hline
\end{tabular}

As cultivares de cenoura quando armazenada em embalagens de PVC, após os 20 dias de armazenamento, apresentaram reduções de $68 \%$, $71 \%$ e $76 \%$ na perda de massa fresca de raízes de cenoura 'Brasília', 'Alvorada' e 'AF620', respectivamente, em comparação com as raízes armazenadas a granel.
A redução de massa fresca de raízes de cenoura das três cultivares armazenadas em embalagens de PVC e a granel apresentou comportamento quadrático, atingindo aos 20 dias de armazenamento perdas de 7,51 e 29,13 g $100 \mathrm{~g}^{-1}$, respectivamente (Figura 1).

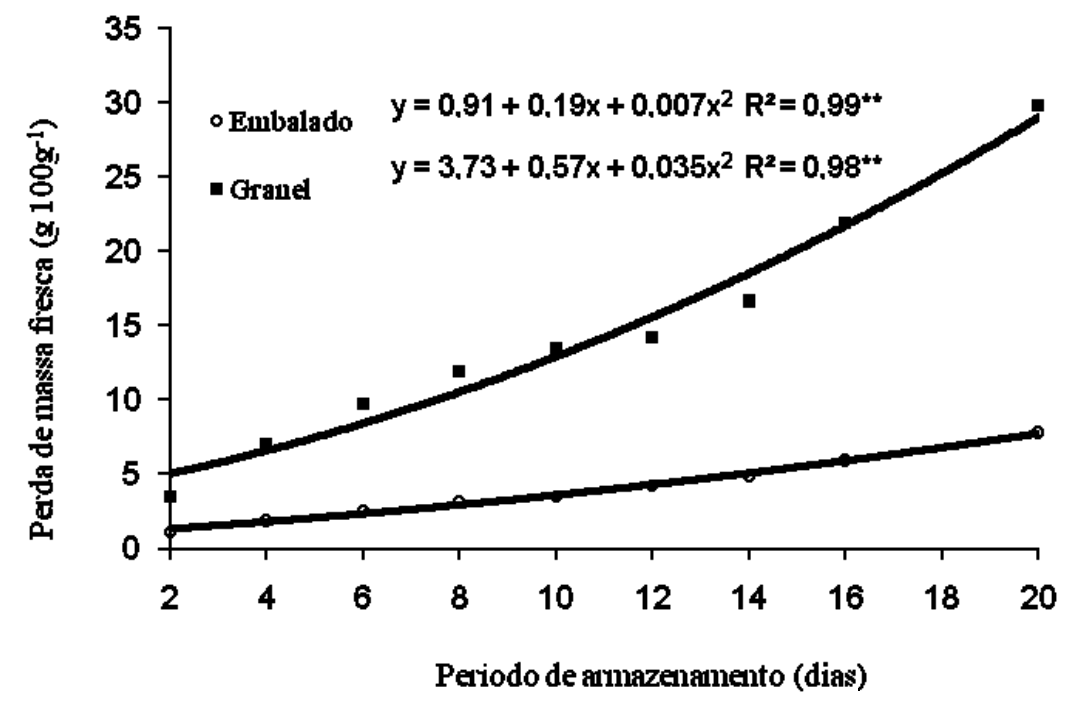

Figura 1. Redução de massa fresca de raízes de cenouras embaladas em filme plástico de policloreto de vinila (PVC) e a granel, em função do período de armazenamento. Ponta Grossa, UEPG, 2007. 
Tal fato se deve aos processos respiratórios e de transpiração que ocorrem nos vegetais (Gorris; Peppelenbos, 1992). Entretanto, mesmo armazenada a granel, a redução de massa fresca de raízes foi de $22 \%$ aos 16 dias, sendo inferior aos $24 \%$ relatados por Caron, Jacomino e Kluge (2003) para cenoura cv Brasília aos 4 dias de armazenamento e $40 \%$ e $24 \%$ aos 8 e 4 dias de armazenamento, respectivamente, obtidos por Oliveira et al. (2001) para cenoura cv Brasília. Os resultados do presente trabalho também diferem dos relatados por Apeland e Baugerod (1971), que obtiveram reduções de massa fresca de 3 a $4 \%$ ao dia. A perda de água, além do murchamento, causa perda de brilho e tornam as raízes de cenouras mais susceptíveis às podridões (SHIBAIRO; UPADHYAYA; TOIVONEN, 1997). Estas diferenças podem estar relacionadas à forma de cultivo, época de produção, condições de armazenagem, principalmente umidade relativa e a diferenças varietais.

Para as raízes embaladas em $\mathrm{PVC}$, a redução de massa fresca limitou-se a 5,7\% aos 16 dias, o que é bastante satisfatório quando leva-se em consideração os $10 \%$ relatados por Oliveira et al. (2001) quando embalou as raízes de cenouras com filme de PVC e armazenou pelo mesmo período.
Para número de cenouras com brotos, avaliado até 20 dias após o início do armazenamento, houve interação significativa apenas entre as cultivares e formas de armazenamento, ou seja, os cultivares apresentam respostas distintas ao número de cenouras brotadas nas duas formas de armazenamento. Houve efeito isolado dos períodos de armazenamento sobre o número de cenouras com brotos.

A porcentagem de cenouras com brotos foi maior quando embaladas em PVC do que a granel (Tabela 1). Quando armazenada a granel, a 'AF1620' e a 'Alvorada' apresentaram menor suscetibilidade à brotação que a 'Brasília', e quando armazenadas em embalagem de PVC a 'Alvorada' não diferiu da 'Brasília'. Independente da cultivar, houve resposta quadrática para a porcentagem de cenouras com brotos. Maior porcentagem foi obtida quando as cenouras foram armazenadas durante um período de 19 dias. A partir desse ponto, houve redução no número de brotos em função da perecibilidade das cenouras (Figura 2). Oliveira et al. (2001) também relataram a ocorrência em elevada proporção de brotações adventícias e de radicelas nas raízes, provavelmente em função do microclima formado dentro da embalagem.

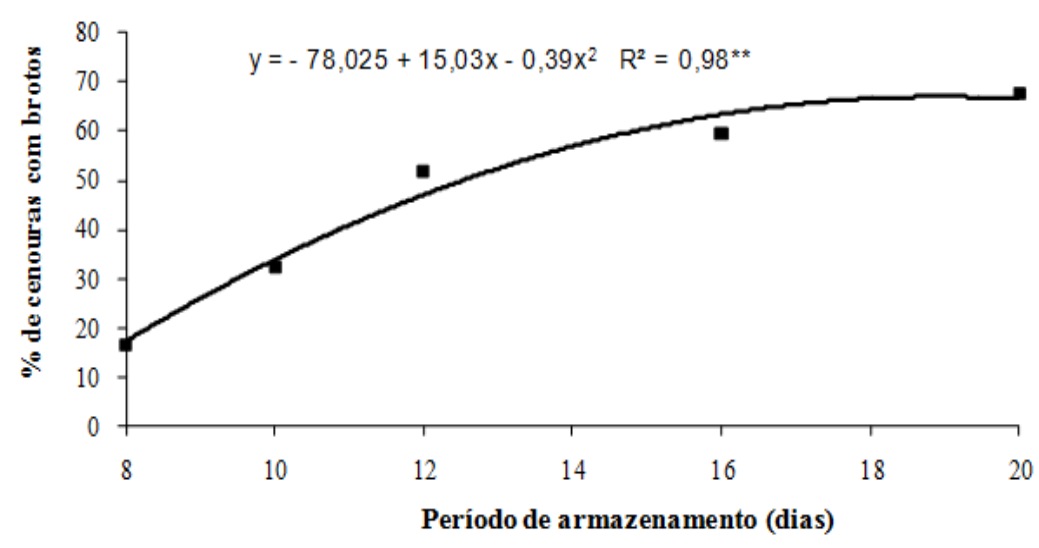

Figura 2. Porcentagem de raízes de cenouras com brotações em função do período de armazenamento com o uso de filme de PVC. Ponta Grossa, UEPG, 2007. 
A porcentagem de cenouras com radicelas foi influenciada significativamente pela interação dos fatores formas de armazenamento e épocas de avaliação e efeito isolado para os fatores cultivares.

O aumento no período de armazenamento para as cenouras embaladas em PVC ocasionou um maior número de cenouras com radicelas, com máximo (93,7\%) observado aos 20 dias de armazenamento. Por outro lado, quando armazenadas a granel, houve um decréscimo de $57 \%$ no número de cenouras com radicelas do $8^{\circ}$ até $13^{\circ}$ dia de armazenamento e um acréscimo de $247 \%$ do $13^{\circ}$ ao $20^{\circ}$ dia de armazenamento, essa diminuição do percentual de cenouras com raízes deve-se ao ressecamento das radicelas e quebra das mesmas, não sendo possível observá-las a olho nu (Figura 3).

As cultivares Alvorada e AF1620 apresentaram maior tolerância à formação de radicelas que a cultivar Brasília (Tabela 2). E as cenouras embaladas em PVC tiveram 414\% a mais de enraizamento quando comparada com o armazenamento a granel (Tabela 2).

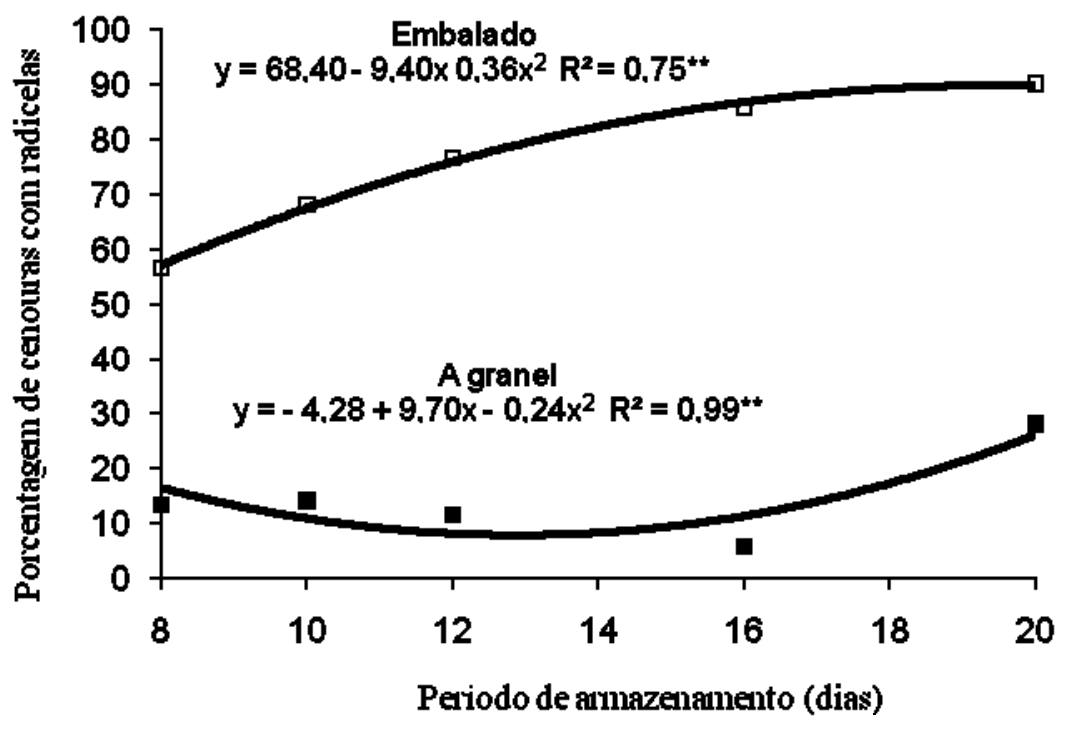

Figura 3. Porcentagem de raízes de cenouras com radicelas embaladas em filme plástico de policloreto de vinila (PVC) e a granel em função do período de armazenamento. Ponta Grossa, UEPG, 2007.

Tabela 2. Porcentagem de cenouras com radicelas em função das cultivares e forma de armazenamento, após 20 dias de armazenamento. Ponta Grossa, UEPG, 2007. Ponta Grossa, UEPG, 2007).

\begin{tabular}{lc}
\hline Cultivar & Porcentagem de cenouras com radicelas \\
\hline Brasília & $54,7 \mathrm{~A}^{*}$ \\
Alvorada & $37,5 \mathrm{~B}$ \\
AF1620 & $43,0 \mathrm{~B}$ \\
\hline Forma de armazenamento & \\
\hline Embalada em filme plástico de PVC & $75,5 \mathrm{~A}$ \\
A granel & $14,7 \mathrm{~B}$ \\
\hline CV $(\%)$ & 30,28 \\
\hline
\end{tabular}

*Médias na mesma coluna, seguidas por letras iguais, não diferem significativamente a 5\% de probabilidade pelo teste de Tukey. 
Houve efeito significativo da interação de cultivares com formas de armazenamento sobre o percentual de raízes de cenouras com podridões armazenadas até 20 dias.

Quando armazenada em embalagem de PVC, a 'Brasília' apresentou o maior número de raízes com podridões, porém não diferiu da 'Alvorada' (Tabela 1). Por outro lado, quando armazenadas a granel, não houve diferença entre as cultivares para podridão de raízes, não verificando, em sua totalidade, o aparecimento de podridão mole nas raízes de cenoura (Tabela 1). Isto se deve a baixa umidade relativa média do ambiente, o que não proporcionou condições favoráveis ao desenvolvimento de patógenos. Não ocorreu um aumento significativo de podridões com o tempo (dado não demonstrado), diferindo de Oliveira et al. (2001), que observaram sintomas de podridões por fungos do gênero Aspergillus e Fusarium a partir do oitavo dia de armazenamento.

Em relação à concentração de $\beta$ caroteno não houve interação e efeito isolado dos fatores cultivares, formas e períodos de armazenamento, o que foi constante ao longo do tempo, apresentando em média 3,73, 4,67 e 5,41 mg $100 \mathrm{~g}^{-1}$, respectivamente, para as cultivares Brasília, Alvorada e AF 1620. Por estarem localizados em gotas lipídicas ou em cromoplastídeos protegidos por lipoproteínas os carotenóides apresentam grande estabilidade (LIMA et al., 2004). O que concorda com Lima et al. (2001) que encontraram valores de 8,7 a $10 \mathrm{mg} .100 \mathrm{~g}^{-1}$ de carotenóides para cenoura 'Nantes', e a concentração de $\beta$ caroteno foi de 49-71 \% dos carotenóides totais (LIMA et al., 2004). Sua concentração pode variar com o desenvolvimento da raiz (HEINONEN, 1990), com o genótipo (SIMON et al., 1989) e com as condições climáticas (HARDH, 1975). Já sua composição varia com a cultivar, estágio de maturação, clima e local de produção (Gross, 1991). Os principais carotenóides encontrados na cenoura são o $\alpha$ e o $\beta$ caroteno (SIMON et al., 1989), que auxiliam na prevenção de doenças e são usados na indústria de alimentos (PINHEIRO-SANT'ANA et al., 1998).
Diante dos resultados, pode-se concluir que de maneira geral a perda de peso foi menor na 'Alvorada'. As perdas por podridões, formação de radicelas e brotamento foram menores na 'AF1620' e 'Alvorada'. O teor de carotenóides é maior nas cultivares AF1620 e Alvorada e é constante durante o armazenamento no escuro. A redução de massa fresca foi o principal fator de perda no armazenamento a granel no escuro, que a partir do $13^{\circ}$ dia apresentou sintoma aparente de murcha, ocasionando restrição para a comercialização, com perda média de $13 \%$ da massa fresca.

\section{Conclusão}

As cenouras armazenadas com filme plástico de policloreto de vinila (PVC) mantiveram-se viáveis comercialmente por até 12 dias. Quando armazenadas à granel apresentaram perda de peso superior a 5\% em 4 dias, não sendo viável para o comércio. A embalagem de filme plástico de policloreto de vinila (PVC) proporcionou condições que restringiram a perda de peso de cenouras em aproximadamente um terço da perda quando armazenada a granel. No entanto, simultâneamente ocorreram condições favoráveis ao brotamento, formação de radicelas e podridões.

Em relação às cultivares, a 'Alvorada' foi a mais suscetível a perda de peso e a 'Brasília' apresentou mais brotações quando armazenada à granel. O teor de carotenóides foi constante em todo o período de armazenamento pra as três cultivares.

\section{Referências}

APELAND, J.; BAUGEROD, H. Factors affecting weight loss in carrot. Acta Horticulturae, The Hague, v. 20, n. 1, p. 92-97. 1971.

CARON, V. N.; JACOMINO, A. P.; KLUGE, R, A. Conservação de cenouras Brasília tratadas com cera. Horticultura Brasileira, Brasília, v. 21, n. 4, p. 597-600. 2003. 
CHITARRA, M. I .F.; CARVALHO, V. D. Cenoura: qualidade e industrialização. Informe Agropecuário, Belo Horizonte, v. 10, n. 120. p. 73-75, 1984.

EMPRESA BRASILEIRA DE PESQUISA AGROPECUÁRIA - EMBRAPA - CNPH. Situação das hortaliças no Brasil, em 2006. 2006. Disponível em: <http://www.cnph.embrapa.br/paginas/hortalicas em_numeros/situacao_hortalicas_brasil_producao_ tomate_2006.pdf $>$. Acesso em: 10 abr. 2008.

GORRIS, L. G. M.; PEPPELENBOS, H. W. Modified atmosphere and vacuum packaging to extend the shelf life of respiring food products. HortTechnology, Stanford, v. 2, n. 3, p. 303-309. 1992.

GROSS, J. Pigments in vegetables: chlorophylls and carotenoids. New York: Avi, Van Nostrand Reinhold Company Inc. 1991.

HARDH, J. E. The influence of the environment of the Nordic latitudes on the quality of vegetables. Plant Food and Human Nutrition, Netherlands, v. 25, n. 1, p. 43-56. 1975.

INSTITUTO ADOLFO LUTZ. Normas analíticas do Instituto Adolfo Lutz. Métodos químicos e físicos para análise de alimentos. 3. ed. São Paulo: Instituto Adolfo Luiz, 1985.

HEINONEN, M. I. Carotenoids and provitamin A activity of carrot (Daucus carota L.) cultivars. Journal of Agriculture and Food Chemistry, Washington, v. 38, n. 3, p. 609-612. 1990.

KADER, A. A. Post-harvest technology of horticultural crops. Oakland: University of California, 1992. 296 p.

KRONKA, S. N.; BANZATTO, D. A. ESTAT: sistema para análise estatística versão 2. 3. ed. Jaboticabal: FUNEP, 1995. $247 \mathrm{p}$.

LIMA, K. S. C.; GROSSI, J. L. S.; LIMA, A. L. S.; ALVES, P. F. M. P.; CONEGLIAN, R. C. C.; GODOY, R. L. O.; SABAA-SRUR, A. U. Efeito da irradiação ionizante $\mathrm{g}$ na qualidade pós-colheita de cenouras (Daucus carota L.) cv. Nantes. Ciência e Tecnologia de Alimentos, Campinas, v. 21, n. 2, p. 202-208. 2001.
LIMA, K. S. C.; LIMA, A. L. S.; FREITAS, L. C.; DELLA-MODESTA, R. C.; GODOY, R. L. O. Efeito de baixas doses de irradiação nos carotenóides majoritários em cenouras prontas para o consumo. Ciência $e$ Tecnologia de Alimentos, Campinas, v. 24, n. 2, p. 183193. 2004.

LUENGO, R. F. A.; CALBO, A. G. Armazenamento de hortaliças. Brasília: Embrapa Hortaliças, 2001. 242 p.

MUKAI, M. K.; KIMURA, S. Investigação das práticas pós-colheita e desenvolvimento de um método para análise de perdas de produtos hortícolas. Viçosa, MG: CENTREINAR, 1986. $253 \mathrm{p}$.

OLIVEIRA, R. A.; ROCHA, I. de B.; SEDIYAMA, G. C.; PUIATTI, M.; CECON, P. R.; SILVEIRA, S. de F. R. Coeficientes de cultura da cenoura nas condições edafoclimáticas do Alto Paranaíba, no Estado de Minas Gerais. Revista Brasileira de Engenharia Agrícola e Ambiental, Campina Grande, v. 7, n. 2, p. 280-284, 2003.

OLIVEIRA, V. R.; GIANASI, L.; MASCARENHAS, M. H. T.; PIRES, N. de M.; VIANA, M. C. M. Embalagem de raízes de cenoura 'Brasília' em filme de PVC. Ciência e Agrotecnologia, Lavras, v. 25, n. 6, p. 1321-1329, 2001.

PINHEIRO-SANT'ANA, H. M.; STRINGHETA, P. C.; BRANDÃO, S. C. C.; PÁEZ, H. H.; QUEIRÓZ, V. M. $\mathrm{V}$. Evaluation of total carotenoids, $\alpha$ and $\beta$ - carotene in carrots (Daucus carota L) during home processing. Ciência e Tecnologia de Alimentos, Campinas, v. 18, $\mathrm{n}$. 1, p. 39-44, 1998.

SHIBAIRO, S. I.; UPADHYAYA, M. K.; TOIVONEN, P. M. A. Postharvest moisture loss characteristics of carrot (Daucus carota L.) cultivars during short-term storage. Scientia Horticulturae, Amsterdan, v. 71, n. 1, p. 1-12, 1997.

SIMON, P. W.; WOLFF, X. Y.; PETERSON, C. E.; KAMMERLOHR, D. S. High carotene mass carrot population. Hortscience, Alexandria, v. 24, n. 1, p. 174175. 1989. 